\title{
The thermal properties of mortars modified by the effect of combining polymers and SCMs
}

\author{
Belbachir B. ${ }^{1,2}$, Benosman A.S. ${ }^{1,2,3 *}$, Taïbi H. ${ }^{1}$, Mouli M. ${ }^{2}$, Senhadji Y.2,4 \\ 1 Faculty of Exact and Applied Sciences, Laboratory of Polymer Chemistry LCP, University of Oran 1, \\ Ahmed Benbella, BP 1524, El Mnaouer, Oran 31000, Algeria. \\ 2 Department of Civil Engineering, Laboratory of LABMAT, ENPO Maurice Audin, Oran, Algeria. \\ 3 Higher School of Applied Sciences, ESSA-Tlemcen, Bel Horizon, 13000 Tlemcen, Algeria. \\ 4 Department of Civil Engineering, University of Mustapha Stambouli, Mascara, Algeria. \\ * Corresponding Author: amre20022000@yahoo.fr
}

\begin{tabular}{l} 
Received: 29-01-2018 Revised: 14-03-2018 \\
\hline Abstract. The thermal performance of the building materials is relevant to any use of \\
composite materials, especially in relation to constructions where it is desirable to have high \\
specific heat, low thermal conductivity and slight or no decrease of stiffness upon heating. \\
The thermal coefficients of composite mortars made up of mixtures of combining styrene \\
polyacrylic SPA Latex and supplementary cementitious materials SCMs were measured at \\
different ages (7, $14,28,60,90$ and 120 days). So, in order to determine the thermal \\
conductivity, the calorific capacity and thermal diffusivity of SCM-modified mortars, it \\
seemed interesting to evaluate the influence of adding the SPA Latex (0.5\%, $1 \%$ and $2 \%$ w) on \\
the properties of these mortars when exposed to a quick thermal conductivity meter based \\
on standard ISO $8302-91$. The highest thermal conductivity of 1.51 W.m- ${ }^{-1} \cdot \mathrm{K}^{-1}$ was observed \\
with the samples containing only plain cement. It decreased with the increase of SPA latex \\
percentages. The lowest values of thermal coefficients were obtained with the samples \\
prepared with SPA polymer at $2 \%$ and SCMs. In this way, the results obtained highlight the \\
beneficial effect of combining SPA polymer and SCM materials as thermal insulation in \\
comparison with other insulation materials. In fact, using SCMs as cement substitutes \\
reduces the energy consumption. These composite mortars address problems related to \\
environmental pollution by $\mathrm{CO}_{2}$ emissions, and can be recommended as materials for energy \\
efficiency in buildings.
\end{tabular}

Key words: Pozzolana, Silica fume, Latex, Thermal coefficients, Sustainable Materials.

\section{Introduction}

The reduction of energy consumption in the building sector is a major challenge in order to cope with the scarcity of fossil energy resources and the problem of climate change (Neville, 1996). Today, the insulation of buildings has become a necessity; it is an efficient and cost-effective way to meet the challenge of reducing energy consumption.

Currently, in the cement industry, $\mathrm{CO}_{2}$ emissions and raw material consumption are mainly targeted in order to reduce their environmental impact. The use of industrial mineral byproducts, such as silica fume (Belbachir et al. 2016; Hassan et al. 2012) or Algerian natural pozzolana (Belbachir, 2017; Ghrici et al., 2006; Kaid et al., 2009; Senhadji et al., 2014; Siad et al., 2013), in composite materials generally involves technological advantages and significant energy savings as well as $\mathrm{CO}_{2}$ emission reductions. This should be consistent with the concept and objectives of sustainable development.

For decades, polymer adjuvants have been widely used in civil engineering and are still increasingly used, due to the diversity of properties they can offer (Ohama, 1995). In the modified formulations, the latex significantly improves the paste consistency, adhesion to the support and especially the mechanical properties of the cured material (Ohama, 1997). Thus, 
Polymer-Mortar Composites based on mineral additions are necessary for energy efficiency in buildings (Belbachir et al. 2016; Benosman et al. 2015).

The purpose of the present work is to study the impact of the combination of latex polymer (Tekweld) and supplementary cementitious materials (SCMs) on the thermal response (thermophysical properties) of SCM-based Polymer-Mortar Composites.

\section{Experimental program}

\subsection{Cement (C)}

The type of cement used is Matine CEMII/A, from Lafarge Cement Plant, based in Oggaz (Wilaya of Mascara, Algeria). This cement has a fineness of $4220 \mathrm{~cm}^{2} / \mathrm{g}$, relative density equal to 3.09 $\mathrm{g} / \mathrm{cm}^{3}$ and a compressive strength equal to $48 \mathrm{MPa}$, at 28 days. The chemical and mineralogical compositions of the cement and its clinker are respectively given in Tables 1 and 2 .

Table 1. Elementary chemical composition of cement, natural pozzolan and silica fume (\%w).

\begin{tabular}{|c|c|c|c|}
\hline Elt. & C & Pz & Sf \\
\hline $\mathrm{SiO}_{2}$ & 17.954 & 46.101 & 94.609 \\
\hline $\mathrm{Al}_{2} \mathrm{O}_{3}$ & 4.071 & 16.442 & 0.320 \\
\hline $\mathrm{Fe}_{2} \mathrm{O}_{3}$ & 2.750 & 9.140 & 1.212 \\
\hline $\mathrm{CaO}$ & 58.15 & 9.057 & 0.434 \\
\hline $\mathrm{MgO}$ & 1.768 & 5.341 & 0.385 \\
\hline $\mathrm{SO}_{3}$ & 2.428 & 0.059 & 0.104 \\
\hline $\mathrm{K}_{2} \mathrm{O}$ & 0.661 & 1.338 & 0.527 \\
\hline $\mathrm{Na}_{2} \mathrm{O}$ & 0.205 & 2.257 & 0.113 \\
\hline $\mathrm{P}_{2} \mathrm{O}_{5}$ & 0.107 & 0.729 & 0.010 \\
\hline $\mathrm{TiO}_{2}$ & 0.223 & 2.062 & 0.024 \\
\hline $\mathrm{LOI}$ & 10.720 & 7.110 & 1.980 \\
\hline \multicolumn{4}{|c}{ LOI: loss on ignition. }
\end{tabular}

Table 2. Mineralogical composition of clinker (\%w)

\begin{tabular}{|c|c|c|c|}
\hline $\mathrm{C}_{3} \mathrm{~S}$ & $\mathrm{C}_{2} \mathrm{~S}$ & $\mathrm{C}_{3} \mathrm{~A}$ & $\mathrm{C}_{4} \mathrm{AF}$ \\
\hline \hline 64 & 15 & 8 & 12.16 \\
\hline
\end{tabular}

\subsection{Natural pozzolan $(\mathrm{Pz})$}

The natural volcanic pozzolan is extracted from the deposit of Bouhamidi in the region of BeniSaf (North West of Algeria). The natural pozzolan used in all tests is in the form of powder, resulting from crushed pozzolanic rock, previously steamed for 24 hours at a temperature of 50 ${ }^{\circ} \mathrm{C}$, to remove moisture; they were then ground until the resulting powder can pass through a sieve with an 80-micron mesh (Ghrici, 2006). The chemical composition of ground natural pozzolan is shown in Table 1.

\subsection{Silica fume (Sf)}

The silica fume used in our study is a Ferro-silicon type additive for concrete in aggressive environments, from TECKNACHEM Company (Sidi Bel-Abbes). Its chemical composition is given in Table 1.

\subsection{Polymer (Tk)}

The polymer used (Styrene Polyacrylic "SPA" Latex), known as TEKWELD from TECKNACHEM Company, is a synthetic resin (Latex) in the form of a high density aqueous solution, stable in an alkaline medium, and especially designed to be added to the mixing water of cement mortars or plaster. The main characteristics of the polymer used are summarized in Table 3. 
Table 3. Characteristics of the polymer used

\begin{tabular}{|c|c|c|c|c|}
\hline Characteristics & Shape & Color & Absolute density $\left(\mathrm{g} / \mathrm{cm}^{3}\right)$ & $\mathrm{pH}$ \\
\hline \hline Polymer & Liquid & White (Milk) & $1.05 \pm 0.01$ & 6 \\
\hline
\end{tabular}

\subsection{Sand}

In this experimental study, the silica sand used was of fraction $0 / 5$, and came from the quarry of Nedroma, $60 \mathrm{~km}$ northwest of Tlemcen. Its principal characteristics are given in Table 4. Before use, a granular correction of this sand was conducted by sea sand in order to have a continuous granulometry, according to the granulometric analysis of standardized sand (Figure 1).

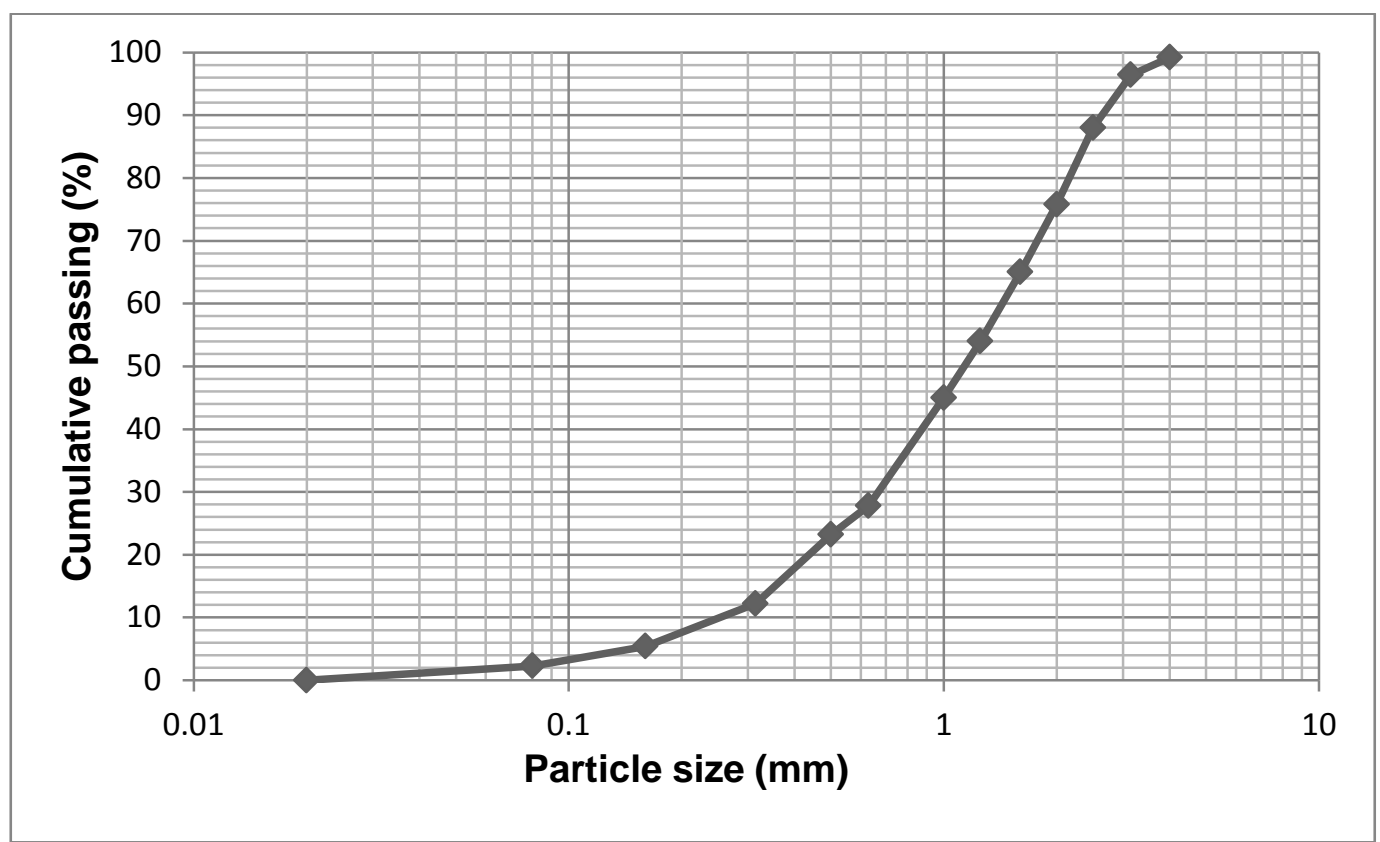

Fig 1. Particle size distributions of Sand

Table 4. Physical properties of sand used.

\begin{tabular}{|c|c|}
\hline Designations & Values \\
\hline \hline Relative density (g/cm3) & 2.63 \\
\hline Fineness modulus & 2.4 \\
\hline Equivalent of sand (\%) & 72 \\
\hline Absorption coefficient (\%) & 1.22 \\
\hline
\end{tabular}

\subsection{Specimen preparation, curing and casting}

It was decided to produce composites based on mineral additives (SCMs) with different polymer contents, i.e. $\mathrm{P} / \mathrm{C}=0.5,1$ and $2 \%$, where $\mathrm{P}$ is the soluble polymer Tk and $\mathrm{C}$ the cement. The mineral additives used are silica fume and natural pozzolan which must necessarily be realized with percentages of (5\% or 10\%) natural pozzolan (Laoufi, et al. 2016; Makhloufi et al. 2015) and 5\% silica fume (Belbachir et al. 2016; Senhadji et al., 2014; Zhang et al. 2016). The mortar used in the present study, consists of the following proportions by mass: 1 cement and 3 sand, with a constant water to cement ratio $\mathrm{W} / \mathrm{C}=0.5$ and superplasticizer/cement $=1.3 \%$ for all composites mortars (Table 5). 
Table 5. The formulations of the different composite mortars

\begin{tabular}{|lc|c|c|c|c|c|c|c|}
\hline \multirow{2}{*}{ Code } & \multirow{2}{*}{ Cement (\%) } & \multicolumn{2}{|c|}{ SCMs (\%) } & \multirow{2}{*}{ Tk (\%) } & \multirow{2}{*}{ Sand (\%) } & \multirow{2}{*}{ W/C } & \multirow{2}{*}{ SP (\%) } \\
\cline { 4 - 7 } & & & Pz & Sf & & & & \\
\hline \hline F0 & $(0 ; 0 ; 0)$ & 100 & - & - & - & 100 & 0.5 & 1.3 \\
\hline F1 & $(5 ; 0 ; 0)$ & 95 & 5 & - & - & 100 & 0.5 & 1.3 \\
\hline F3 & $(10 ; 0 ; 0)$ & 90 & 10 & 0 & - & 100 & 0.5 & 1.3 \\
\hline F5 & $(0 ; 5 ; 0)$ & 95 & 0 & 5 & - & 100 & 0.5 & 1.3 \\
\hline F6 & $(10 ; 0 ; 0.5)$ & 89.5 & 10 & 0 & 0.5 & 100 & 0.5 & 1.3 \\
\hline F7 & $(10 ; 0 ; 2)$ & 88 & 10 & 0 & 2 & 100 & 0.5 & 1.3 \\
\hline F8 & $(0 ; 5 ; 1)$ & 94 & - & 5 & 1 & 100 & 0.5 & 1.3 \\
\hline F9 & $(0 ; 5 ; 2)$ & 93 & - & 5 & 2 & 100 & 0.5 & 1.3 \\
\hline
\end{tabular}

F0: Control Mortar; Pz: pozzolan; Sf: Silica fume; Tk: Tekweld; SP: Superplasticizer.

Mortars and/or composites were cast and compacted mechanically with a shock table (NF EN 196.1, 2005).

1- The molds containing the specimens were covered with a plastic film and stored in the laboratory environment.

2- After this, the specimens were removed from the molds and they were kept in water saturated with lime for 1 day.

3- Afterward, the specimens were removed from the water and they were kept in an environment with a temperature of $20 \pm 2^{\circ} \mathrm{C}$ and a relative humidity of $60 \pm 5 \%$.

\subsection{Thermal coefficients}

A quick thermal conductivity meter (QTM 30) based on standard (ISO 8302, 1991) guarded hot plate apparatus was used to measure the thermal conductivity, calorific capacity and thermal diffusivity of the sample at different ages. The Measurement was performed after the specimens $\left(40 \times 40 \times 160 \mathrm{~mm}^{3}\right)$ were dried in an oven at $100 \pm 3{ }^{\circ} \mathrm{C}$. The thermal coefficients of composite mortars made up of mixtures of combining styrene polyacrylic SPA Latex and SCMs were measured at different ages: 7, 14, 28, 60, 90 and 120 days (Figure 2). The experimental protocol of thermal test is carried out according to the recommendations of ISO 8302 (1991).

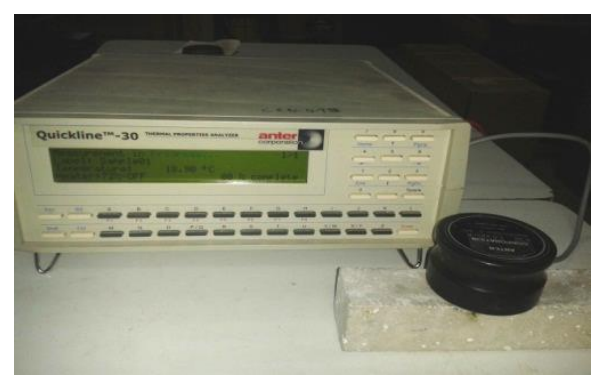

Fig 2. Device (Quickline TM-30 thermal analyzer) with sample for thermal conductivity testing

\section{Results and discussion}

\subsection{Thermal conductivity}

\subsubsection{Effect of natural pozzolan and polymer (Series I)}

The evolution of the thermal conductivity as a function of time is shown in Figure 3. 
It is easy to note that at $7,28,60,90$ and 120 days, the reference mortar has a thermal conductivity that is close to that of natural pozzolan-based composite mortars. At all ages, adding natural pozzolan does not contribute to reducing the thermal conductivity of the composite mortars as compared to that of the reference mortar.

However, there is a slight decrease in the conductivity values as a function of age, for different mortars. These results corroborates with those obtained by Hamadache et al. (2014) and Laoufi, (2015).

Note that at any age, the thermal conductivities of natural pozzolan-based composite mortars modified with the polymer are lower than that of unmodified mortar (reference mortar). Therefore, the incorporation of the Latex polymer into the cementitious mixture causes a significant decline in the thermal conductivity.

The thermal conductivity of the composites $(10 ; 0 ; 0.5)$ and $(10 ; 0 ; 2)$, at 28 days, dropped by $18 \%$ and $47 \%$, respectively, as compared with that of the unmodified mortar. This is certainly due to the formation of the Tekweld polymer film.

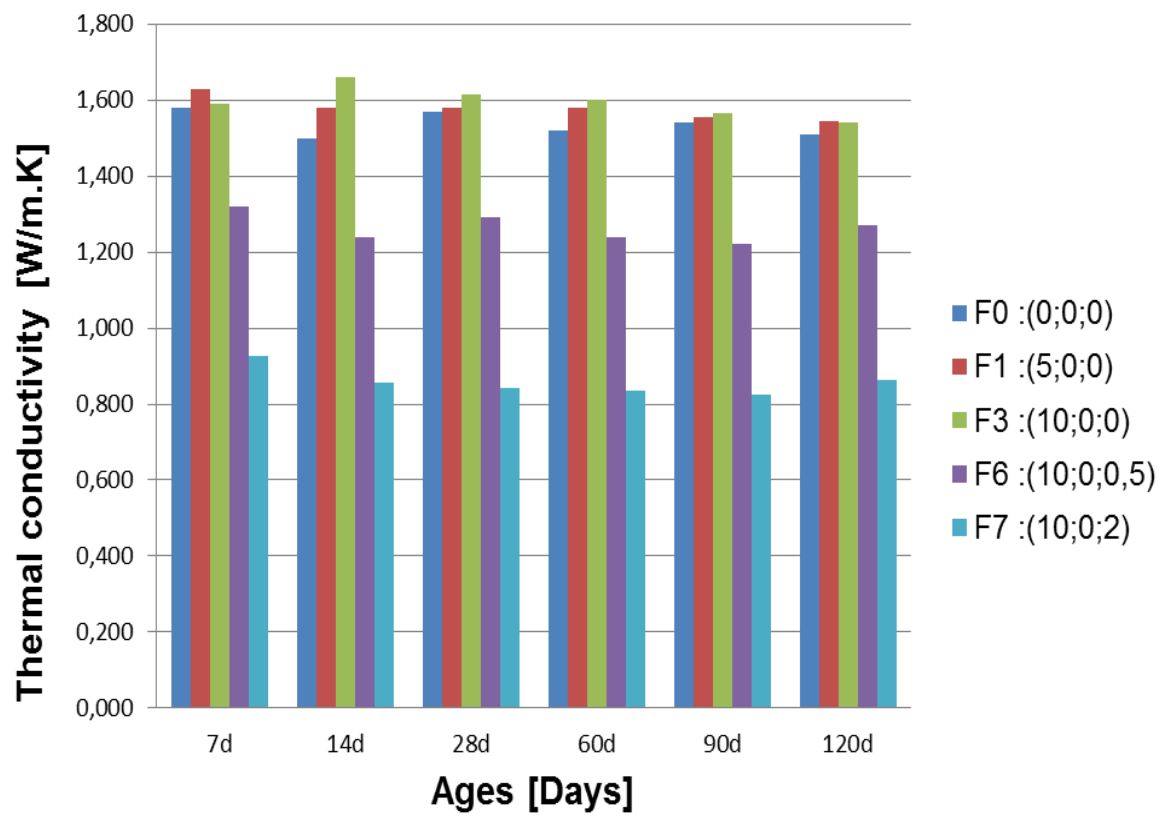

Fig 3. Evolution of thermal conductivity over time (Series I)

\subsubsection{Effect of silica fume and polymer (Series II)}

Figure 4 shows that the conductivity value of the silica-based mortar is slightly higher than that of the control mortar; it tends to remain constant beyond the young age. The addition of silica fume does not reduce the conductivity value. It can be assumed that the silica fume consists of silica nanoparticles that infiltrate into the matrix to act as filler. Thus, the silica fume causes the cementitious matrix to be impermeable, since the number of pores will decrease over time until the stabilization of the cementitious hydration mechanism. On the other hand, it is observed that the values of this conductivity decrease slightly with age, for the different mortars.

At 7 and 28 days, the conductivity of the composite containing $1 \%$ polymer $(0 ; 5 ; 1)$ decreases by $28 \%$ and $35 \%$, respectively, as compared to that of the unmodified mortar; on the other hand, it can be noted that the conductivity decreases by $35 \%$ and $44 \%$, respectively, relative to that of the control mortar for $2 \%$ of polymer $(0 ; 5 ; 2)$. 
In the longer term (90 and 120 days), there is a significant decline in the conductivity; it is of the order of $41 \%$ for a substitution rate of $2 \%$ of polymer and about $36 \%$ for a rate of $1 \%$ of polymer. This is due to the formation of the Tekweld polymer film.

The decrease in the thermal conductivity may be due to the effect of the latex on the total porosity, which decreases (Belbachir, 2017). This porosity decline may be explained by the clogging of pores by the latex film.

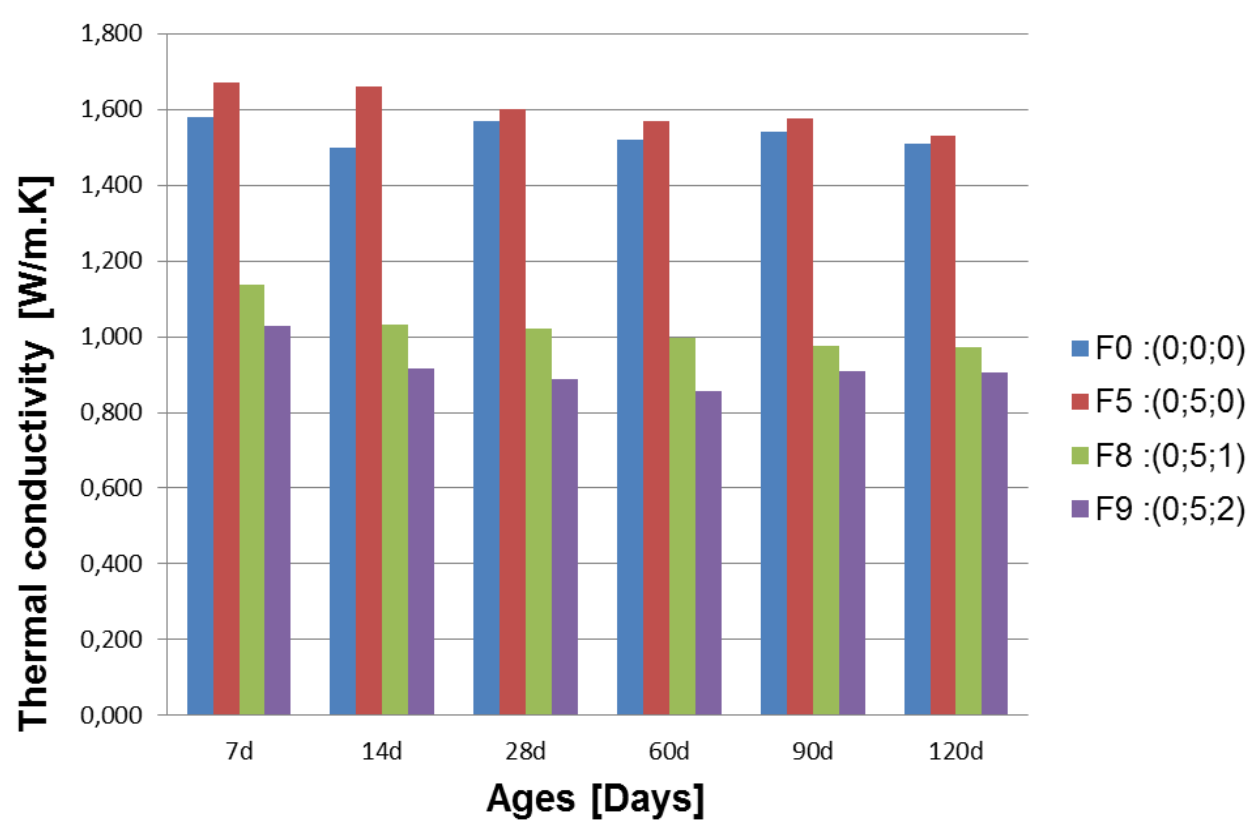

Fig 4. Evolution of the thermal conductivity over time (Series II)

\subsubsection{Effect of natural pozzolan, silica fume and polymer (Series III)}

Figure 5 illustrates the variation of the thermal conductivity as a function of time. In the case of mortars with additions, i.e. the pozzolan and silica fume, it is found that, at all ages, the mineral additions do not contribute to the reduction of the thermal conductivity. On the contrary, an increase was recorded at the young age ( 7 and 14 days).

The thermal conductivity values from this study are found to be slightly high for mineral-based mortars. It is found that the higher the densities of the mortars containing SCMs, the higher the thermal conductivity (See section 3.2). In addition, some studies (Demirboga, 2003) have reported that the thermal conductivity increases with the density of the composite. The last mentioned findings support our results.

The graphic illustration in the figure clearly shows the effect of the polymer on conductivity. It is noted that conductivity decreases when the substitution rate increases.

It would therefore seem that polymer-mortar composites are poor thermal conductors since their conductivity decreases as the polymer content increases. These results could be attributed to the overall porosity of the cementitious matrix, to the density decline of the polymer-based composite (lightness of the composite mortar), and especially to the formation of the polymer film (Belbachir, 2017). These results corroborates with those obtained by Latroch et al. (2016).

On the other hand, knowing that air has a thermal conductivity 25 times lower than that of water, it is clear that when the pores are filled with air (instead of water), the composite mortar will have a lower thermal conductivity (Laoufi, 2015). The thermal conductivity decreases with age and polymer content; this is due to the reduction in the density of the composite and to the 
increase in its air content. Benosman et al. (2017) reported that the increases in air content with increasing polymer particles reduce the thermal bridges in the matrix and contribute to improving composite insulation.

For the different ages mentioned, the two mortars containing $2 \%$ polymer, i.e. $(10 ; 0 ; 2)$ and $(0$; $5 ; 2)$, undergo very significant reductions in their thermal conductivities as compared to that of the control mortar and to those of mortars containing mineral additions, without latex. Their thermal properties are therefore better.

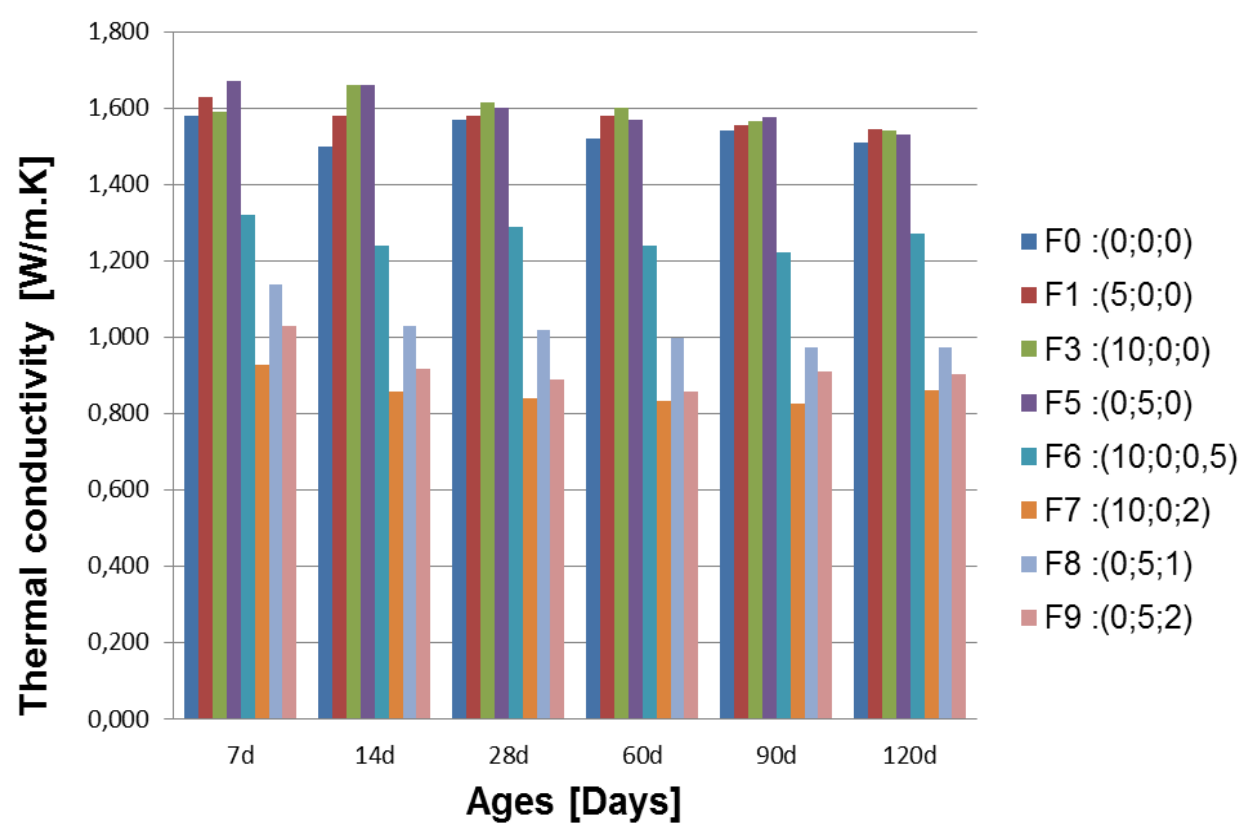

Fig 5. Evolution of the thermal conductivity over time (Series III)

As a result, several authors (Aattache et al., 2013; Benosman et al., 2013; Elalaoui, 2012a,b; Fu et al., 1997; Latroch et al. 2016) reported that the thermal conductivity decreases as the polymer content in the composite increases. Because, the thermal conductivity of the polymer is lower than plain cement or SCMs. The findings of the present investigation are therefore consistent with those reported by the above mentioned authors.

\subsection{Correlation between thermal conductivity and density of the composite mortars}

The corresponding relationship between thermal conductivity and density of the composite is shown in Figures 6 and 7. The thermal conductivity $\lambda\left(\mathrm{W} \cdot \mathrm{m}^{-1} \cdot \mathrm{K}^{-1}\right)$ decreases with decreasing apparent density $\left(\mathrm{g} / \mathrm{cm}^{3}\right)$. The derived correlation is of the linear type: $\lambda=1.438 \mathrm{x}-1.3476$ (which yields a correlation coefficient $\mathrm{R}^{2}=0.9907$ ) for the series $\mathrm{I}$ and $\lambda=1.5419 \mathrm{x}-1.5421$ (which $\mathrm{R}^{2}=0.9986$ ) for the series II. The thermal conductivity of materials depends upon many factors, including their structure, material mixture proportioning, type of aggregate inclusions, density, porosity, etc (Benosman et al. 2017; Gouasmi et al. 2016). So, the decrease in thermal conductivity is also related to the less density of the Tekweld polymer film content in the matrix that results in less density. Consequently, this low density will allow the lightening of Tekweldmodified mortar composites. The thermal insulating effect of Latex polymer is most attractive and indicates a high and promising potential for development. These results corroborates with those obtained by Latroch et al. (2016). 


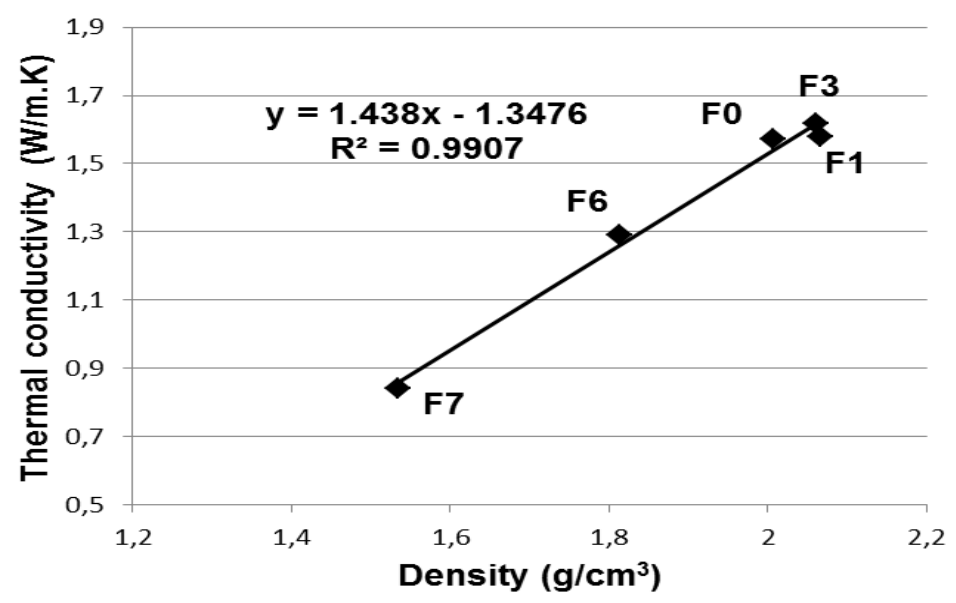

Fig 6. Relationship between thermal conductivity and density of composites (series I)

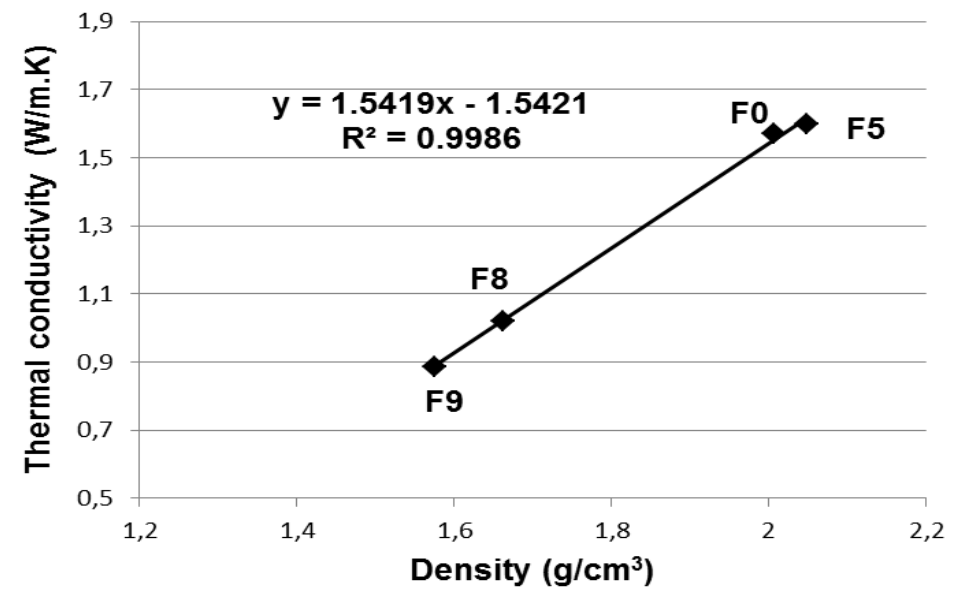

Fig 7. Relationship between thermal conductivity and density of composites (series II)

\section{Conclusions}

The results obtained allow us to draw the following conclusions:

- The thermal conductivities of mineral-based Polymer-Mortar Composites, $(10 ; 0 ; 0.5)$, $(10 ; 0 ; 2),(0 ; 5 ; 1)$ and $(0 ; 5 ; 2)$, are lower than those of mortars without polymer, hence the beneficial effect of Tekweld polymer on the thermal properties.

- On the other hand, the thermal conductivity values are found to be slightly high for mineral-based mortars (without Tk polymer).

- The thermal conductivity decreases as the styrene polyacrylic (SPA) Latex content in the composite increases. Because, the thermal conductivity of the SPA polymer is lower than plain cement or SCMs.

- The decrease in the thermal conductivity may be due to the effect of the latex "SPA" on the total porosity, which decreases. This porosity decline may be explained by the clogging of pores by the latex film.

- The thermal conductivity decreases with age and polymer content; this is due to the reduction in the density. It is found that the smaller the densities of the SPA polymerbased composite mortars, the lower the thermal conductivity.

- The correlations and coefficients indicate a good linear correlation between thermal conductivity and density in composites. Thus, incorporation of Tk polymer into the 
cement matrix reveals the ability of composites to provide a reliable level of thermal insulation.

\section{Acknowledgments}

We would like to express our gratitude for the financial support of the Algerian project CNEPRU B00L01UN310120130068. We are also grateful to Mr M.T. Gouasmi and Mr O. Hasnaoui General Director of HASNAOUI Companies Group, The TEKNACHEM Algeria.

\section{References}

Aattache, A., Mahi, AEK., Soltani, R., Mouli, M., \& Benosman A.S. (2013). Experimental study on thermomechanical properties of Polymer Modified Mortar, Materials and Design, 52, 459-469.

Belbachir, B. (2017). Résistances mécaniques et durabilité des matériaux composites modifiés par ajout de polymères, Thèse de Doctorat Es-Science, Université d'Oran 1, Ahmed Benbella, Oran, Algérie.

Belbachir, B., Benosman, A.S., Taïbi, H. (2016). Mineral-based composite materials for energy efficiency in buildings, Key Engineering Materials (KEM), 678, 123-134.

Benosman, A.S., Latroch, N., Belbachir, B., Taibi, H., Ayed, K., \& Mouli, M. (2015). Matériaux Composites Mortier-Polymère à bases des additions minérales : Durabilité dans un environnement à tendance acide. Rencontres Universitaires de Génie Civil AUGC'15, 27-29 May, Bayonne, France. https://hal.archives-ouvertes.fr/hal-01167753

Benosman, A.S., Mouli, M., Taibi, H., Belbachir, M., Senhadji, Y., Bahlouli, I., \& Houivet, D. (2013). Effect of addition of PET in the thermal properties of Polymer-Mortar Composite materials, Chemistry and Materials Research, 5, 21-26.

Benosman, A.S., Mouli, M., Taibi, H., Belbachir, M., Senhadji, Y., Bahlouli, I., \& Houivet, D. (2017). The chemical, mechanical and thermal properties of PET-Mortar Composites containing waste PET, Environmental Engineering and Management Journal, 16(7), 1489-1505.

Demirboga, R. (2003). Influence of mineral admixtures on thermal conductivity and compressive strength of mortar, Energy Building, 35, 189-192.

Elalaoui, 0. (2012a). Optimisation de la formulation et de la tenue aux hautes températures d'un béton à base d'époxyde, Thèse de Doctorat en Cotutelle, Cergy-pontoise, France \& Université de Tunis El Manar, Tunisie.

Elalaoui, O. Ghorbel, E., Mignot, V., \& Ben Ouezdou, M. (2012b). Mechanical and physical properties of epoxy polymer concrete after exposure to temperatures up to $250^{\circ} \mathrm{C}$, Construction and Building Materials, 27, 415-424.

EN 196-1. (2005). Methods of testing cement - Part 1: determination of strength. European Committee for Standardization, CEN.

Fu, X. \& Chung, D.D.L. (1997). Effect of Silica fume, Latex, methylcellulose, and carbon fibers on the thermal conductivity and specific heat of cement paste, Cement and Concrete Research, 27(12), 1799-1804.

Ghrici, M. (2006). Etude des propriétés physico-mécaniques et de la durabilité des ciments à base de pouzzolane naturelle, Thèse de Doctorat d'état, USTMB d'Oran, Algérie.

Ghrici, M., Kenai, S., Mansour-Said, M., \& El-Hadj Kadri, A. (2006). Some engineering properties of concrete containing natural pozzolana and silica fume, Journal of Asian Architecture and Building Engineering, 5(2), 349-354.

Gouasmi, M.T, Benosman, A.S., Taïbi, H., Belbachir, M., \& Senhadji Y. (2016). The physico-thermal properties of mortars made of composite aggregates "PET-siliceous sand", Journal of Materials and Environmental Science, 7(2), 409-415.

Hamadache, M., Mouli, M., Bouhamou, N., Chaib, O., Benosman, A.S. \& Dif, F. (2014). he Thermal Properties of Natural Pozzolan and Energy Efficiency in Buildings, Journal of Control Science and Engineering, 2(2), 120-127. 
Hassan, A.A.A., Lachemi, M., \& Khandaker Hossain, K.M.A. (2012). Effect of metakaolin and silica fume on the durability of self-consolidating concrete, Cement and Concrete Composites, 24 (3), 801-807.

IS08302. (1991). Thermal Insulation, Determination of Steady-State Areal Thermal Resistance and Related Properties--Guarded-Hot-Plate Apparatus. The International Organization for Standardization. On line at: https://www.iso.org/standard/15422.html.

Kaid, N., Cyr, M., Julien, S., \& Khelafi, H. (2009). Durability of concrete containing a natural pozzolan as defined by a performance-based approach, Construction and Building Materials, 23, 3457-3467.

Laoufi, L. (2015). Comportement mécanique et structurel du béton dans un environnement agressif, Thèse de Doctorat Es-Sciences, ENP-Oran, Maurice Audin, Algérie.

Laoufi, L., Senhadji, Y., \& Benosman, A.S. (2016). A study of natural pozzolan mortars exposed to sulfate as energy efficient building material, Key Engineering Materials (KEM), 678, 109-122.

Latroch, N., Benosman, A.S., Bouhamou, N., Belbachir, B., Senhadji, Y., Taïbi, H., Mouli, M. (2016). Testing of composite mortars based on supplementary cementitious materials: estimating durability and thermal properties, International Journal of Engineering Research in Africa, 27, 27-35.

Makhloufi, Z., Chettih, M., Bederina, M., Hadj Kadri, E.l., \& Bouhicha, M. (2015). Effect of quaternary cementitious systems containing limestone, blast furnace slag and natural pozzolan on mechanical behavior of limestone mortars, Construction and Building Materials, 95, 647-657.

Neville, A.M. (1996). Properties of Concrete, Fourth edition John Wiley \& Sons, Inc., New York, USA, 844.

Ohama, Y. (1995). Hand Book of Polymer-Modified Concrete and Mortars: Properties and Process Technology. Building Materials Science Series, Noyes Publications: USA, Park Ridge, N.J. p 236.

Ohama, Y. (1997). Recent progress in concrete-polymer composites, Advanced Cement Based Materials, 5, 31-40.

Senhadji, Y., Escadeillas, G., Mouli, M., Khelafi, H. \& Benosman, A.S. (2014). Influence of natural pozzolan, silica fume and limestone fine on strength, acid resistance and microstructure of mortar, Powder Technology, 254, 314-324.

Siad, H., Kamali-Bernard, S., Mesbah, H.A., Escadeillas, G., Mouli, M., \& Khelafi, H. (2013). Characterization of the degradation of self-compacting concretes in sodium sulfate environment: Influence of different mineral admixtures, Construction and Building Materials, 47, 1188-1200.

Zhang, Z., Zhang, B., \& Yan, P. (2016). Comparative study of effect of raw and densified silica fume in the paste, mortar and concrete, Construction and Building Materials, 105, 82-93. 